\title{
Direitas partidárias na América Latina do século XXI
}

\author{
Jean Lucas Macedo Fernandes*
}

\section{Resumo}

\begin{abstract}
Através de levantamento bibliográfico e de contraposições críticas dos debates recentes da literatura, este trabalho realiza um balanço acerca da relação entre conservadorismo e dinâmica partidária na América Latina contemporânea. $O$ enfoque recai sobre as transformações econômicas e políticas do contexto internacional e a maneira como o espectro ideológico conservador tem articulado suas demandas aos partidos políticos. Especificamente, transportaremos esta relação entre partidos e conservadorismo para pensar o caso brasileiro. A conclusão geral é de que os partidos à direita - que acolhem as pautas conservadoras - têm se adaptado com sucesso ao jogo democrático, em meio ao recrudescimento de discursos conservadores, reativos às ações progressistas que ganharam força ao longo dos governos de esquerda dos anos 2000.

Palavras-chave: conservadorismo; partidos políticos; ideologia.
\end{abstract}

\begin{abstract}
Through a bibliographical review and critical contrasts of the recent debates in the literature, this paper analyzes the relationship between conservatism and partisan dynamics in contemporary Latin America. The focus is on the economic and political transformations of the international context and the way in which the conservative ideological spectrum has articulated its demands to the political parties. Specifically, we will use this association between parties and conservatism to think the Brazilian case. The general conclusion is that the parties on the right - which embrace the conservative agenda - have successfully adapted to the democratic rules amid the recrudescence of conservative discourses, reactive to progressive actions that have gained momentum throughout the 2000s leftist governments.

Keywords: conservatism; political parties; ideology.
\end{abstract}

\section{O "velho conservadorismo" em cheque}

Ao contrário do que geralmente se pensa, em uma interpretação superficial acerca do conceito, o conservadorismo, nas últimas décadas, vem se mostrando adepto de transformações no interior do capitalismo. Opõe-se a uma visão estática de mundo (Gibson, 1996; Fretel, 2011) típica do chamado "velho conservadorismo" (Giddens, 1995), no qual a continuidade da ordem é assegurada por comunidades morais como Igreja, família e Estado.

\footnotetext{
* Mestre e doutorando em Ciência Política pelo Instituto de Filosofia e Ciências Humanas, da Universidade Estadual de Campinas (IFCH/UNICAMP). E-mail: jeanlucasmf@gmail.com.

Agradeço a Kelly Camargo, doutoranda em Demografia pela UNICAMP, e Thuany Figueiredo, mestra em Linguística pela UNICAMP, pelas leituras. Agradeço, também, aos pareceristas da Leviathan, pelas sugestões de revisão do texto.
} 
Para esta corrente de pensamento, originada no Antigo Regime, as obrigações são sempre anteriores aos direitos e criadas por Deus. De maneira sucinta, o "velho conservadorismo" defende a naturalização da hierarquia, da aristocracia e da primazia da comunidade sobre o indivíduo, bem como a importância do sagrado. Em autores como Edmund Burke, a visão conservadora não é retrógada - a tradição nunca é estática, mas precisa estar equilibrada pela correção ou pela reforma. O olhar para frente deve se basear no olhar para trás. A inovação, então, não ignora a sabedoria dos ancestrais e das instituições que passaram no teste do tempo. $\mathrm{O}$ indivíduo não deve se sobrepor a comunidade, pois este representa uma interminável cadeia de gerações - os direitos, então, devem frisar a comunidade. De acordo com esta cadeia de pensamento, portanto, a tomada de decisão baseada no voto individual é perigosa - logo, estes conservadores se opõem à democracia. Como sintetiza Mannheim (1981), este tipo de conservadorismo reage negativamente à modernidade burguesa e liberal, uma vez que sua base social é aristocrática.

Romano (1994, p. 26) desenvolve argumento semelhante, identificando que para autores clássicos do pensamento conservador", a soberania popular representa "o grande perigo e o grande vício do liberalismo e das Luzes democráticas". O modelo ideal de governo e de sociedade, além de uma base social moralista e religiosa, deve ser autoritário - uma vez que, para essas correntes do conservadorismo, o povo não é soberano e precisa ser controlado de maneira tirânica e absoluta. Os "bons governos" são, assim, aqueles próximos às monarquias e às ditaduras.

Nesse sentido, o conservadorismo corresponde a uma corrente particular de pensamento. Atualmente, nas democracias ocidentais, o "velho conservadorismo" cedeu espaço a ideais conservadores que enxergam nas transformações e nas propostas por mudanças (econômicas, políticas e sociais) as estratégias discursivas necessárias para suas sobrevivências no mundo contemporâneo. Adaptando-se, então, às regras do jogo democrático, diversos setores conservadores aderiram aos partidos políticos².

\footnotetext{
${ }^{1}$ Para um debate aprofundado sobre pensadores conservadores clássicos, ver Romano (1981) e Giddens (1995).

2 Não estamos tratando aqui os partidos conservadores como compostos somente por uma classe social. Reconhecemos, seguindo a perspectiva analítica de Gibson (2000), que a fragmentação entre as diferentes classes sociais gera apoios a partidos conservadores distintos, com modos e interesses também distintos. Para o caso brasileiro, isso será bastante observado, visto que desde as reformas político-administrativas da Era Vargas, as elites brasileiras - principalmente aquelas ligadas diretamente ao aparelho estatal - são heterogêneas (Kaysel, 2015).
} 
Em termos relacionais, os partidos conservadores se situam à direita de seus pares no espectro ideológico (Bobbio, 1995; Middlebrook, 2000; Fretel, 2011), e adquirem significações variadas, a depender do contexto político (Altman et. al., 2009). Como já se sabe, a chave de leitura a partir do continuum direita-esquerda teve suas origens na Revolução Francesa ${ }^{3}$ e adquiriu significados marcantes a partir do século XIX. Esquerda e direita se converteram, então, em marcas de identidade e passaram a funcionar como atalhos cognitivos que ajudam a estruturar o mundo político (Bobbio, 1995; Wiesehomeier e Doyle, 2012). Postos em perspectiva comparada, esses eixos devem ser compreendidos sempre em caráter relacional: primeiramente, precisam ser contextualizados (Franzmann, 2010). De acordo com Bobbio (1995), na contemporaneidade, o que tem caracterizado a esquerda é a defesa do igualitarismo, ao qual a direita se opõe e combate. A luta pela igualdade social, para o autor, remonta à própria história das esquerdas contra o "inimigo comum" que é a propriedade privada - que seria o maior obstáculo à igualdade entre as pessoas.

Ao longo do século XX, o conflito entre esquerda e direita se acentua, ganhando contornos mais definidos e extremos. Seu ápice veio não apenas durante a Segunda Guerra Mundial (19391945) em si - nas disputas ideológicas entre o Nazi-fascismo e o Comunismo - mas também nos desdobramentos da mesma, com a Guerra Fria (1945-1989). A polarização crescente, que adquiriu nomenclaturas diversas ${ }^{4}$, repercutiu tanto nas relações econômicas quanto políticas entre os países, e no interior de cada um deles.

Diante do exposto, este artigo procura explorar as relações existentes entre os partidos e o discurso conservador, especialmente a partir da virada para o século XXI. Para tal, serão feitas considerações gerais sobre esta articulação no contexto latino-americano. Na sequência, traçamse alguns apontamentos acerca do acolhimento das pautas conservadoras na política brasileira recente, na qual nos deteremos mais a fundo. A conclusão sintetiza o balanço bibliográfico, apontando para o fortalecimento da relação entre os ideais conservadores e as suas implementações, através de partidos à direita do espectro ideológico.

\section{O conservadorismo na América Latina: passado e presente}

\footnotetext{
${ }_{3}^{3}$ Para maiores informações acerca do surgimento da díade, ver Cruz (2015), Giddens (1996) e Bobbio (1995).

${ }^{4}$ Por exemplo: União Soviética x Estados Unidos; Comunismo x Capitalismo; Democracia x Autoritarismo, etc.
} 
Desde o início dos processos de transição democrática, em fins dos anos 1970, a América Latina enfrentou cenários distintos entre seus países, revelando a heterogeneidade políticopartidária que predomina no continente. Alcántara e Freidenberg (2002) e Luna e Zechmeister (2005) apontam que os sistemas partidários latino-americanos apresentam configurações bastante diversas. Elas vão desde casos com tradições partidárias sólidas (Argentina, Chile e Uruguai), passando por países que abrigam sistemas que mantinham tradições dos períodos democráticos anteriores combinados a novos partidos emergentes nas transições (Brasil e Bolívia), até sistemas com partidos historicamente debilitados e sem um marco mínimo de organização e continuidade no tempo (El Salvador, Peru, Venezuela e Guatemala).

Diante de um quadro complexo e diverso, os partidos latino-americanos sofreram profundas transformações ao longo dos anos 1980 e 1990 - período em que se articulavam as novas leis e ações democráticas com memórias e resquícios do autoritarismo anterior (Smith e Ziegler, 2009). Dessa relação, surgiram clivagens importantes para a configuração do sistema político nesses países, levando inclusive a níveis de cristalização programática diferentes entre eles (Luna e Zechmeister, 2005). De acordo com Alcántara e Freidenberg, as transformações a que foram submetidos os partidos nos anos subsequentes ao término de seus regimes autoritários se deram tanto por fatores endógenos quanto exógenos:

Os elementos endógenos centraram-se em questões tradicionais como as relativas a lideranças mais ou menos caudilhescas, a enfrentamentos entre os Poderes do Estado, ao impacto da corrupção. Por seu lado, o fator exógeno por excelência foi a derrocada do socialismo real e a perda de um referente sólido ideológico e prático para grandes setores da esquerda latino-americana. Entre as questões de caráter político-institucional que tinham a ver com as modificações registradas no universo partidário, se encontravam as mudanças realizadas nos próprios textos constitucionais, as leis partidárias e as leis eleitorais. Nenhum país latino-americano deixou de fazer essas modificações, com maior ou menor profundidade, durante esse período. Finalmente, as questões de outra índole não estritamente políticas também estiveram na origem das mudanças acontecidas, fosse como conseqüência da crise econômica que assolou a região durante a década de 1980 e que enterrou definitivamente o modelo de substituição de importações e a centralidade do Estado vigentes quase durante meio século, fosse como resultado da aparição de valores pós-materialistas e das mudanças registradas nas sociedades (Alcántara e Freidenberg, 2002, pp. 143). 
Estes processos, como demonstram os autores, afetaram tanto o formato numérico dos sistemas de partidos - levando o continente ao multipartidarismo ${ }^{5}$ - quanto a relação do eleitorado com as agremiações, resultando em elevada rejeição à classe política e aos partidos em geral. Esta última constatação é compartilhada e atualizada por Albala e Vieira (2014). No entanto, há outra variável explicativa, resultante dessas transformações endógenas e exógenas que incide diretamente sobre a discussão que se propõe este trabalho: trata-se da polarização ideológica. No contexto latino-americano, a separação entre direita e esquerda auxilia na previsão das filiações partidárias, bem como ajuda a orientar as atitudes políticas dos cidadãos e das classes políticas (Alcántara, 2004b; Wiesehomeier e Doyle, 2012).

A divisão ideológica na América Latina é guiada, em grande medida, pelas pautas vigorantes na Europa e nos Estados Unidos (Cueva, 1989; Cruz, 2015). Um exemplo disso é a clássica separação entre esquerda e direita a partir da dicotomia Estado versus mercado. Desde o início do século XX, fenômenos como o Nazi-fascismo, o Comunismo e o Liberalismo são elementos que influenciaram fortemente os debates e as atitudes políticas no continente, resultando tanto em partidos políticos quanto em movimentos sociais orientados a partir de seus eixos.

Cruz (2015) afirma que a posição em relação aos Estados Unidos foi uma importante maneira de balizar esquerda e direita na América Latina, durante a segunda metade do século XX, no contexto da Guerra Fria. De acordo com o autor, a influência dos Estados Unidos, no campo ideológico, foi muito maior sobre o centro liberal e a direita, culminando em um posicionamento favorável à intervenção estrangeira e ao apoio das grandes potências no desenvolvimento econômico do continente. Tal posicionamento se cristalizou na adoção de políticas neoliberais, cuja onda chegou ao continente a partir do final dos anos 1980, em países como Peru, México, Brasil e Argentina (Anderson, 1995).

Além dessa oposição Estado-mercado, há, pelo menos, outras duas dimensões oriundas de processos que, ainda que tenham sofrido influências externas ao continente, adquiririam contornos específicos no debate político latino-americano. Por um lado, tem-se a dimensão do conservadorismo (moral, religioso e nacionalista) versus liberalismo/pluralismo. Como argumenta Alves (2000), a constituição da direita política no mundo contemporâneo tem se dado pela

\footnotetext{
${ }^{5}$ De acordo com Albala e Vieira (2014), a tendência ao bipartidarismo começa a desaparecer, na América Latina, no início dos anos 1990.
} 
articulação dessa face do conservadorismo social ${ }^{6} \mathrm{com}$ a defesa do programa neoliberal. Por outro lado, as formações dos campos ideológicos se dão, também, por meio da separação que leva em consideração as preferências de regime (democracia versus autoritarismo) ${ }^{7}$. De fato, como apontam Alcántara e Valduvieco (2008), a direita latino-americana é bastante diversificada.

Segundo Middlebrook (2000), o conflito entre Igreja e Estado foi um fator central para a formação dos partidos conservadores na América Latina, desde o século XIX. Através deste conflito, foi possível obter fontes poderosas para as divisões intra-elites, bem como conformar bases amplas para a mobilização e a competição política. Por meio de questões religiosas e de cunho moralizante, as elites dos partidos conservadores conseguiram um apelo multiclassista. Outra base importante para a organização política nos países latino-americanos foram as divisões geográficas entre as regiões, assim como as separações entre as elites, resultando em formas de governo mais ou menos centralizadas ${ }^{8}$ (Middebrook, 2000).

Para Codato, Bolognesi e Roeder (2015), estes grupos ${ }^{9}$ ligados ao conservadorismo religioso e moralizante - e muito mais favorável a medidas autoritárias - ganharam força nos anos 1960, como reação aos movimentos reformistas populares que surgiram nesta década. Segundo Cruz (2015), as origens de tais grupos remontam à primeira metade do século XX, no contexto de ascensão do fascismo italiano e do catolicismo reacionário. Tornaram-se, posteriormente, fontes importantes de apoio tanto para os partidos de direita - sobretudo os de matriz cristã (Pierucci, 1987) - quanto para movimentos autoritários. É conhecido, por exemplo, o suporte dos conservadores cristãos e da Igreja aos golpes militares em diversos países, nos anos 1960 e 1970.

Durante esses anos, e com o apoio deste conservadorismo de cunho moral e social, as ditaduras militares latino-americanas ganharam fôlego. Basearam-se em partidos políticos e movimentos que, por diferentes modos, conseguiram agregar vertentes das elites e das camadas populares em torno de um projeto de modernização conservadora, ancorado por regimes

\footnotetext{
${ }^{6}$ Nas palavras da autora: "a revitalização da direita não se manifesta apenas pelo êxito do programa neoliberal em diversas partes do mundo. Uma onda de conservadorismo social constitui a outra faceta da nova direita no mundo contemporâneo. Parece haver um paralelo entre a ofensiva neoliberal e uma simétrica barbarização da vida societária, com os problemas do desemprego, da exclusão social, das várias formas de preconceito (racial, cultural, sexual, religioso etc.) e da escalada da violência em grande parte do mundo capitalista. As soluções conservadoras são as que mais se beneficiam nesse cenário" (Alves, 2000, p. 188).

${ }^{7}$ A reflexão, aqui, se baseia nas três "dimensões ideológicas latentes" propostas por Altman et. al. (2009) para uma classificação dos partidos políticos na América Latina: estatismo; conservadorismo e atitudes em relação ao regime democrático.

${ }^{8}$ Como veremos mais adiante, os partidos de direita brasileiros se originam muito mais dessas bases do que pela clivagem Estado-Igreja, que não conseguiu estruturar nenhum grande partido no país.

9 No Brasil, o exemplo mais claro nesse sentido foram os participantes da "Marcha da Família, com Deus, pela Liberdade" - com grande apoio da Igreja Católica e setores empresariais, no contexto do pré-golpe de 1964.
} 
autoritários, estatistas e repressivos à direita. Como é amplamente apontada pela literatura, a clivagem democracia-autoritarismo acabou sendo um dos principais eixos de divisão entre direita e esquerda na América Latina, durante as décadas de transição democrática (1970-1980) (Luna e Kaltwasser, 2014; Mainwaring, Meneguello e Power, 2000; Roberts, 2012; Middlebrook, 2000). As chamadas "democracias iliberais", que combinam eleições aparentemente livres e justas com medidas autoritárias limitantes de direitos dos cidadãos, tornaram-se a maioria entre os países do continente (Smith e Ziegler, 2009). O autoritarismo, portanto, continuou presente na dinâmica política democrática latino-americana e capitaneado pelos partidos de direita - ainda que estes, recorrentemente, neguem este passado de vínculo com as ditaduras militares (Madeira e Tarouco, 2010).

É sob a mobilização desses diferentes discursos (neoliberal, moralizante e autoritário), e sobretudo a partir dos anos 1980, que os partidos e setores conservadores tem se apresentado ao eleitorado no jogo democrático. Em países com democracias recentes, como é o caso dos latino-americanos, o movimento observado nas últimas décadas é o de reconciliação das agendas da direita civil com os militares, no sentido tanto de retorno quanto de suporte às regras democráticas (Gibson, 1996; Smith e Ziegler, 2009). Como aponta Middlebrook (2000), a presença de partidos conservadores nas transições democráticas latino-americanas não só facilitaram o processo como puderam contribuir para a consolidação do regime subsequente:

onde estes partidos possuem bases organizacionais bem desenvolvidas e podem articular recursos ideológicos ou programáticos que mobilizem substancialmente o apoio do eleitorado, grupos empresariais, proprietários de terras e as elites conservadoras religiosas e militares, eles tem potencial para avançar suas preferências políticas por meios eleitorais ${ }^{10}$ (Middlebrook, 2000, p. 2, tradução minha).

Nesse sentido, os partidos conservadores são responsáveis por canalizar, através de instituições democráticas, as demandas de setores sociais e políticos até então diretamente vinculados aos regimes autoritários. Ao representarem suas pautas na arena eleitoral, esses partidos indicam uma postura favorável à competição político-institucional com as demais agremiações, inclusive as de esquerda. Esta "sinalização" dos partidos conservadores é fundamental para que as eleições aconteçam e os resultados sejam aceitos, posteriormente. Ou

\footnotetext{
${ }^{10}$ No original: "Where these parties have well-developed organizational bases and can articulate and ideological or programmatic appeal that mobilizes substantial electoral support, business groups, landowners, and conservative religious and military elites have the potential to advance their policy preferences through electoral means".
} 
seja, os partidos de direita desempenham um papel importante na legitimação das democracias, por meio do processo eleitoral.

Em se tratando de América Latina, Wiesehomeier e Doyle (2012) demonstram que o eleitorado tem conseguido minimamente adotar posicionamentos coerentes, dentro de uma escala esquerda-direita. Os principais eixos capazes de orientá-los nesse sentido são a oposição Estado-mercado e o posicionamento perante a ideia de igualdade social. Como afirmam Luna e Kaltwasser (2014), a clivagem esquerda-direita no continente é, essencialmente, um conflito ideológico centrado nas políticas redistributivas. No caso do eleitorado mais conservador, suas posições adotam, por vezes, soluções autoritárias como forma de superar conflitos políticos e manter privilégios - além de um apelo à dimensão religiosa e moralista.

Analisando em perspectiva longitudinal, é possível identificar três momentos centrais na trajetória dos partidos conservadores latino-americanos pós-transições ${ }^{11}$. Primeiramente, durante os processos de abertura política em fins dos anos 1970 e início dos anos 1980, esses partidos procuraram se desvencilhar do passado ligado aos regimes autoritários, que muitas de suas lideranças apoiavam. Tratou-se de um período de reacomodação político-partidária, onde partidos e políticos procuraram reorganizar-se de acordo com as novas regras do jogo e os novos padrões de competição eleitoral, sofrendo profundas transformações (Alcántara e Freidenberg, 2002). A segunda fase, a partir de fins dos anos 1980 e ao longo dos anos 1990, marca o auge do sucesso eleitoral dos partidos à direita, na esteira das políticas neoliberais e da legitimidade que o discurso político-econômico do Estado mínimo ganhava em todo o Ocidente. A América Latina adentrou, portanto, na chamada "era do conservadorismo" (Cueva, 1989; Hirschmann, 1992).

A partir da virada do século, com eleições sendo realizadas periodicamente, observou-se um processo de institucionalização quase generalizado entre os partidos latino-americanos, configurando uma tendência geral em direção a certa estabilidade na configuração de seus sistemas partidários $^{12}$ (Alcántara e Freidenberg, 2002; Albala e Vieira, 2014). Esses fatores, de acordo com Luna e Kaltwasser (2014), favorecem o desempenho das esquerdas na arena eleitoral,

\footnotetext{
${ }^{11}$ A análise feita aqui leva em consideração as divisões a grosso modo. Não deixamos de reconhecer, contudo, que em alguns países, os processos de abertura do regime, o retorno ao multipartidarismo e a disputa esquerda-direita obedeceram a padrões específicos - como é o caso do Chile, do México, da Colômbia, do Paraguai e de El Salvador, por exemplo. Para maiores informações acerca destes casos específicos, ver Roberts (2012), Luna e Kaltwasser (2014) e Oliveira e Benetti (2014).

${ }^{12}$ A discussão em torno do grau de institucionalização e estabilização dos partidos da América Latina é muito vasta e polêmica, ocupando uma parte importante dos debates na literatura, principalmente a partir dos anos 1990. Confira, dentre outros: Alcántara (2004a; 2004b), Ames (2003), Mainwaring e Torcal (2005), Mainwaring e Scully (1996).
} 
na medida em que permitiram a elas que articulassem melhor suas forças e estreitassem os laços com o eleitorado, demandando mudanças econômicas e opondo-se às teses da modernização conservadora vigentes.

As eleições de Hugo Chávez na Venezuela, em 1998, iniciam a terceira fase da dinâmica político-partidária, que é justamente a de ascensão das esquerdas e declínio da direita (Roberts, 2012). Essa fase ficou conhecida como a "maré rosada" dos anos $2000^{13}$ (Codato, Bolognesi e Roeder, 2015). Outros países que passaram a ser governados por partidos à esquerda logo na sequência, além da própria Venezuela, foram Brasil, Argentina, Bolívia, Equador e Uruguai (Oliveira e Benetti, 2014). A literatura procurou classificar esses governos de esquerda, colocando casos como Chile, Brasil e Uruguai (democracias mais consolidadas) enquanto "esquerda moderada"; ao passo que Venezuela, Equador, Argentina e Bolívia foram enquadrados como "esquerda populista" ou "radical" (Weyland, 2009; Levitsky e Roberts, 2011).

Dentre os motivos que explicam esse declínio dos partidos conservadores, uma primeira interpretação da literatura se associa a fatores externos, como a diminuição da hegemonia norteamericana sobre o continente (Panizza, 2009; Hershberg, 2010) e, consequentemente, sobre os partidos liberais e conservadores, que perdem uma fonte importante de apoio. No entanto, ganham destaque na literatura as variáveis de ordem estrutural, como o esgotamento e as falhas visíveis das políticas neoliberais; as crises econômicas e o aumento das desigualdades sociais decorrentes.

Luna e Kaltwasser (2014) e Reid (2007) seguem por essa linha argumentativa, atribuindo a crise da direita partidária à exaustão do projeto de modernização conservadora capitaneado pelas elites e pelos políticos conservadores, desde os anos 1980. A reação popular, nesse sentido, veio por meio do apoio a projetos políticos que se opunham à ideia do Estado mínimo e propunham soluções mais inclusivas e de caráter social aos problemas econômicos. As esquerdas foram as responsáveis por liderar esses discursos de redução das desigualdades.

A partir de então, como argumentam Luna e Kaltwasser (2014), as dificuldades eleitorais da direita estão diretamente relacionadas aos níveis de desigualdade socioeconômica que prevalecem na América Latina. Para os autores, tais dificuldades representam uma barreira aos partidos de direita, visto que muitos dos projetos que defendem não procuram soluções profundas para essa questão. Este argumento ganha ainda mais força, quando se leva em conta

\footnotetext{
${ }^{13}$ Sobre o crescimento das esquerdas na América Latina, ver: Weyland (2009); Levitsky e Roberts (2011); Hershberg e Cameron (2010), Panizza (2005) e Lupu (2009).
} 
que o eleitorado latino-americano é sensível à questão da desigualdade e dos papeis que cabem ao Estado na dimensão econômica (Wiesehomeier e Doyle, 2012).

Para além dessas explicações de ordem conjuntural e estrutural, outra chave analítica para pensarmos o declínio da direita na América Latina e os seus dilemas é proposta por Roberts (2012). Para esse autor, o eixo explicativo centra-se na dimensão mais propriamente partidária, e a sua relação com os projetos políticos e os interesses que predominam no continente desde os anos 1980. O declínio dos partidos conservadores está diretamente associado aos interesses das elites: esses partidos teriam se apresentado como "dispensáveis" na proteção desses interesses. Como já haviam sugerido Mainwaring, Meneguello e Power (2000), as elites mais conservadoras e neoliberais da América Latina preferem acessar diretamente o Estado e os policymakers, ao invés de adentrarem nos partidos políticos e construírem organizações mais sólidas.

Roberts (2012) observa que essas elites têm outros recursos - poder econômico, controle das mídias etc - que tornam secundárias as estratégias diretamente partidárias. Para tais elites, é muito mais vantajoso e efetivo investir dinheiro em propagandas, canais de televisão, organizações sociais e movimentos, do que em partidos. São através desses outros meios que, para o autor, a direita tem conseguido influenciar diretamente o policymaking. Portanto, as elites neoliberais, por muitas vezes, não reivindicaram suas demandas e reformas via partidos conservadores. Como sintetiza o autor,

De fato, onde mesmo os partidos estatistas e populistas históricos poderiam contar na adesão ao Consenso de Washington, partidos de direita foram amplamente dispensáveis aos processos de liberalização dos mercados, e as elites tiveram pouca necessidade de investir em organizações partidárias enquanto canais institucionalizados de representação de interesses (Roberts, 2012, pp. 11-12, tradução minha) ${ }^{14}$.

Nesse sentido, três fatores de ordem partidária-organizacional (articulados entre si) ajudam a explicar a perda de espaço da direita na América Latina. Tem-se o desinteresse das elites em construir intermediários institucionais e representativos fortes, na figura dos partidos - o que contribuiu, por outro lado, para uma maior fragilidade organizacional das agremiações de direita no continente. Por fim, na medida em que o projeto neoliberal foi se mostrando insuficiente na resolução dos problemas socioeconômicos e contribuindo, inclusive, para a atenuação de algumas

\footnotetext{
14 No original: "Indeed, where even historic statist and populist parties could be counted on to adhere to the Washington Consensus, rightist parties were largely dispensable to the process of market liberalization, and elites had little need to invest in party organizations as institutionalized forms of interest representation".
} 
disparidades sociais, os partidos conservadores perderam a legitimidade de uma de suas principais bandeiras. O caminho foi aberto, então, para que soluções estatistas e de welfare ganhassem força dentro das estratégias programáticas dos partidos de esquerda. A popularidade dessas medidas foi notada até mesmo entre o eleitorado que se identifica mais com o campo da direita (Arnold e Samuels, 2011).

Contudo, esse declínio não nos deve fazer pensar que a direita latino-americana está enfraquecida. Ainda que não ocupem majoritariamente os cargos da presidência, as direitas são veículos importantes de atuação no Congresso, nas mídias de massa, nas campanhas eleitorais e nas atividades de lobby e pressão na sociedade civil (Luna e Kaltwasser, 2014). Além disso, os partidos representantes da direita adotam pautas distintas entre os países da América Latina, atribuindo pesos diferentes às questões econômicas, ideológicas, culturais e políticas (Alcántara e Valduvieco, 2008). Esta afirmação nos leva a olhar para os blocos conservadores com mais detalhamento, tendo em vista a complexidade (e a diversidade) de suas atitudes.

Além disso, após a crise econômica de 2008 e suas consequências sobre os governos mais à esquerda, o que tem se assistido é um cenário de fortalecimento dos projetos sociais e econômicos vinculados à direita. Isso tem se dado não apenas via partidos políticos, com o aumento das bancadas conservadoras nos Congressos e no Executivo, mas também por movimentos sociais com utilização de redes sociais e outras formas de mobilização em meio à sociedade civil (Tatagiba, Trindade e Teixeira, 2015; Cruz, Kaysel e Codas, 2015).

Em se tratando da dinâmica eleitoral e o papel dos partidos políticos neste processo, Middlebrook (2000) fornece alguns mecanismos para se pensar representatividade e conservadorismo. O primeiro modelo é o de influência através do clientelismo mediado pelo partido (influence through party-mediated clientelism). Isso se dá através de lobby, subornos, financiamentos de campanha, obtenção de favores e outros meios de influenciar a elaboração de políticas dos governos e as legislações.

O segundo meio de se fazer valer essa representação, e que foi muito forte nos anos 1980 e 1990, é a participação dos partidos conservadores na coalizão de políticas neoliberais (conservative participation in neoliberal policy coalitions). Nos países latino-americanos, muitas das reformas e reorientações econômicas foram promovidas pelos partidos de direita. Para Middlebrook, a participação dessas agremiações nas coalizões neoliberais foi importante para a adaptação das elites - sobretudo econômicas - ao jogo democrático, durante a transição dos 
regimes militares. Além de participarem das pautas políticas, esses grupos foram capazes de mobilizar o apoio eleitoral e, assim, estabelecerem-se nas disputas e campanhas.

Por fim, uma terceira via de inclusão das pautas das elites se dá através da hegemonia desses setores na sociedade civil por organizações não-partidárias (conservative hegemony exercised through nonparty organizations of civil society). Isso se daria em diferentes frentes, resultando em influências múltiplas. Incluem-se as privatizações diversas: escolas, universidades, hospitais, mídias, empresas etc. Nesse sentido, os canais partidários não seriam os alvos principais das elites, que por conta de seu poder econômico, encontrariam na sociedade civil um terreno mais propício para atenderem seus interesses.

É em torno desse terceiro ponto que residem algumas divergências na literatura, quanto aos espaços de influência (e seus limites) para os partidos conservadores (Roberts, 2012). No caso brasileiro, será observado que a ideia das elites dominando os canais partidários e votando sempre nessas agremiações não se sustenta fortemente (Mainwaring, Meneguello e Power 2000), o que nos leva a se aproximar mais da perspectiva de Roberts (2012) do que de Gibson (1996) ou Middlebrook (2000).

\section{Especificidades e trajetórias dos partidos à direita no Brasil}

Ao transpormos, para o caso brasileiro, essas considerações em torno do papel dos partidos e da representação dos setores tradicionalmente associados à direita, algumas especificidades precisam ser pontuadas. Uma primeira observação diz respeito ao que Middlebrook (2000) e Gibson (1996) chamam de núcleo constitutivo dos partidos conservadores (core constituency), que trariam sua própria definição conceitual. Além de ser um emprego que pouco ajuda na caracterização do que seria, de fato, um partido de direita ${ }^{15}$ (Cruz, 2015), para o caso brasileiro, tal definição se torna insuficiente, em se tratando dos partidos conservadores.

Mainwaring, Meneguello e Power (2000) demonstram que os setores mais ricos da população não apoiam, necessariamente, os partidos de direita brasileiros: suas bases populares residem mais no personalismo e no clientelismo, e menos nas posições ideológicas e elitistas.

\footnotetext{
15 Esclarecendo o argumento, Cruz (2015, p. 19) diz que "a correlação entre orientação política e composição social é importante porque nos dá elementos preciosos para entender os posicionamentos desses partidos, mas ao tomá-la como critério de definição do que seja um partido de direita ou de esquerda enredamo-nos em uma operação tautológica".
} 
Nesse sentido, os autores identificaram que há duas vertentes do conservadorismo brasileiro contemporâneo: uma popular (clientelista e personalista) e outra elitista (programática), com diferentes partidos da direita representando cada uma das esferas. Assim, a definição desses partidos por meio dos seus core constituencies se mostra exígua para o caso brasileiro, na medida em que apenas contempla uma vertente do conservadorismo que tem se apresentado no país. Como demonstra Kaysel (2015), a heterogeneidade é uma marca do conservadorismo brasileiro desde o século XIX.

Outra observação importante para o Brasil reside na dinâmica eleitoral-partidária em si. A constituição e o funcionamento dos partidos conservadores no Brasil guardam, desde a experiência democrática do período 1946-1964 diversos aspectos que incidem diretamente sobre o multipartidarismo e o lugar da direita no pós-1985. O protagonismo que o Estado passou a assumir sobre a formação e a atuação partidos a partir de 1930 (Souza, 1976), associado às experiências autoritárias (1937-1945 e 1964-1985) e aos traços conservadores e autoritários de nossa cultura ${ }^{16}$ (lanni, 1989), foram moldando a maneira de se compreender o que são e que bandeiras carregam os partidos conservadores brasileiros. Esta noção foi se alterando ao longo do século XX, devido às mudanças políticas, econômicas e sociais dos períodos históricos pelos quais o país atravessou. Foi também, durante esse último século, que os conflitos entre direita e esquerda se acentuaram em todo o mundo ${ }^{17}$ (Cruz, 2015).

A história brasileira dos dois últimos séculos foi marcada por traços de continuidade das práticas e dos atores políticos ao longo dos processos de ruptura institucional (Hagopian, 1996; Power, 2000), incluindo aí o autoritarismo, golpismo ou anti-democracia. Como pontua lanni (1989), muito desta longa vigência do sentimento anti-democrático se deve à frequente união das forças das burguesias nacional e estrangeira, associando-se às altas hierarquias das forças

\footnotetext{
${ }^{16}$ Segundo Cândido (1990), o conservadorismo é o "maciço central" que dominaria nossa vida intelectual. Para lanni (1989), isso se manifestaria, por exemplo, na transformação das questões sociais em questão de polícia - um traço do profundo autoritarismo da sociedade brasileira. Uma revisão abrangente sobre a genealogia das direitas brasileiras é feita em Kaysel (2015).

${ }^{17}$ Para os casos latino-americanos, alguns eventos históricos foram especialmente importantes para definir os campos da direita e da esquerda. Como principais exemplos, podemos citar os desdobramentos da Revolução Mexicana (1910) e o posicionamento político-econômico no campo internacional em relação aos Estados Unidos, com o advento do Neoliberalismo (Cruz, 2015). Além destes fatos, não se pode deixar de mencionar a Revolução Cubana (1959) e as ditaduras militares dos anos 1960 e 1970.
} 
armadas e da Igreja Católica, bem como setores de classe média e intelectuais ${ }^{18}$. Trata-se de um arranjo que, segundo o autor, reaparece em momentos de crise do monopólio do poder estatal.

Ao longo desses processos de ruptura institucional e de manutenção de atitudes políticas, foram preservadas, também, algumas características nos partidos conservadores brasileiros. De acordo com Mainwaring, Meneguello e Power (2000), a ênfase na política estadual e local, a menor disciplina partidária (quando comparados com os partidos de esquerda), o baixo nível de fidelidade partidária e a dependência do clientelismo seriam os principais elementos definidores das agremiações de direita no país. Em termos de bases partidárias, essas características ficariam mais evidentes nos menores municípios e, dentre estes, aqueles que apresentam baixo Índice de Desenvolvimento Humano (IDH) (Avelar e Walter, 2008; Montero, 2011).

São dessas localidades que, tradicionalmente, os partidos de direita extraem a maior quantidade de apoio político do eleitorado (Power, 1996). Baseando-se na premissa de Scott (1969), de que a mistura de pobreza com dependência material de laços clientelísticos pode sustentar chefes políticos no poder, Montero (2011) argumenta que são nos chamados "grotões" do Brasil (Norte e Nordeste) que os partidos de direita apresentam melhor performance eleitoral justamente por serem compostos por chefes políticos sustentados por essas práticas. Além dessa, outra premissa central no argumento do autor é o de que a primazia dos conservadores se dá no nível subnacional. Nessas localidades, eles foram capazes de estabelecer modelos de continuísmo e uma forte tendência ao governismo - ou seja, a consolidação das máquinas políticas locais das elites conservadores está diretamente associada as suas capacidades de acessarem recursos estatais.

Levando em consideração essas características, uma definição possível para a direita brasileira seria aquela que adota uma "prática conservadora que tem como seu núcleo central a dominância de áreas de interesse subnacional e o uso dessas bases para sustentar a influência dos conservadores na política nacional19" (Montero, 2011, p. 6, tradução minha). Este processo de conexão político-eleitoral inclui os partidos, mas não é necessariamente dirigido por eles - seja por conta da vinculação personalista das elites (Mainwaring, Meneguello e Power, 2000) ou pela identificação direta que fazem com suas bases regionais, sem intermédio partidário (Power, 2000).

\footnotetext{
${ }^{18}$ Há que se destacar também, na atual conjuntura política nacional, o peso que vem adquirindo as altas hierarquias da burocracia federal - em especial o Judiciário, a Polícia Federal e o Ministério Público.

${ }^{19}$ No original: "conservative rule that has as its core the dominance of subnational bailiwicks and the use of these bases to sustain the influence of conservatives in national politics".
} 
Por conta da dependência do aparato estatal para as suas sobrevivências, os partidos de direita tendem a se enfraquecer quando não controlam o Estado. As baixas taxas de fidelidade de seus quadros (Melo, 2004), somadas à pouca identificação do eleitorado com essas legendas ${ }^{20}$ (Mainwaring, Meneguello e Power, 2000; Kinzo, 2005), fazem com que as organizações partidárias de direita necessitem amplamente dos recursos estatais para se perpetuarem. Os trabalhos de Borges (2010) e Ribeiro (2014) evidenciam esse argumento, ao demonstrarem que fora do governo, partidos como o PFL/DEM ${ }^{21}$ quase desapareceram - tendo como comparação o período em que dominavam governos estaduais ${ }^{22}$ e eram o principal aliado do PSDB (Partido da Social Democracia Brasileira) no plano nacional (1995-2002).

Entretanto, as bases sociais da direita não se concentram apenas nas regiões menos desenvolvidas socioeconomicamente e nos menores municípios. Codato, Bolognesi e Roeder (2015) demonstram que, por um lado, a chamada "direita tradicional" (PFL/DEM, PP, PL/PR e $\mathrm{PTB}^{23}$ ) não está necessariamente presente apenas nas regiões Norte e Nordeste. Por outro lado, evidenciam que há setores da direita que têm crescido nos grandes centros urbanos, principalmente na região Sudeste - atraindo, em especial, lideranças de cunho personalista, como religiosos e apresentadores de televisão. Essa direita mais "urbana" e moralista tem sido denominada de "nova direita" (Pierucci, 1987; Oliveira e Benetti, 2014; Codato, Bolognesi e Roeder, 2015).

Não há na literatura, ainda, um consenso sobre o que seria essa nova direita e qual exatamente o seu tamanho, em termos eleitorais. Para o caso brasileiro pós-transição democrática, Souza (1992) foi uma das primeiras autoras a propor e a definir tal expressão, como uma maneira de compreender o surgimento das forças conservadoras em um contexto de ascensão do Neoliberalismo e de crítica ao modelo estatista que vigorava desde Vargas ${ }^{24}$.

Essa nova direita, então, ganha sucesso e legitimidade em suas ideias por conta do esgotamento de um modelo econômico desenvolvimentista que tinha como condutor central o Estado. Soma-se a isso o apoio das potências estrangeiras nesta empreitada neoliberal, como

\footnotetext{
${ }^{20}$ Cabe mencionar que a baixa identificação do eleitorado não é um fenômeno exclusivo dos partidos de direita. Kinzo (2005) demonstra que, à exceção do Partido dos Trabalhadores (PT) e do Partido do Movimento Democrático Brasileiro (PMDB) (em menor escala), as legendas são pouco conhecidas pelos eleitores no país.

${ }^{21}$ Partido da Frente Liberal, renomeado “Democratas" (DEM) em 2007.

22 Montero (2011, p. 20) apresenta um dado interessante: entre 1982 e 2006, 77\% dos governadores das regiões Norte e Nordeste pertenciam a algum partido conservador.

${ }^{23}$ Respectivamente, Partido Progressista, Partido Liberal/Partido da República e Partido Trabalhista Brasileiro.

${ }^{24}$ Algumas considerações importantes em torno do conceito de "nova direita", em termos mundiais, são feitas por Oliveira e Benetti (2014).
} 
forma de flexibilizar as relações comerciais, abrir os mercados e elevar o grau de dependência financeira do país. De acordo com Souza (1992), três fatores foram importantes para a criação de uma corrente neoliberal organizada no Brasil.

O primeiro deles foi o Plano Cruzado (1986), que causou grande frustração na população e contribuiu para a cristalização de uma tendência antiestatista na sociedade como um todo. 0 segundo fator foi a Assembleia Constituinte (1987-1988), cujos debates revelaram a erosão de certo consenso em torno do legado de Vargas e da centralidade do papel do Estado na economia. As elites divergentes, então, aproveitaram o momento de formulação de uma nova Constituição para implantar uma agenda neoliberal e, ao mesmo tempo, denunciar os problemas institucionais do paradigma estatista. Por fim, o Plano Bresser (1987) causou intensa reação da comunidade de negócios, nacional e internacional, que argumentou que os problemas nacionais estavam no setor público, e não no privado. A evidente crise interna do Estado, então, contribuiu para a mudança ideológica na direita.

Tendo em vista esse cenário, três questões emergem como traços distintivos da nova direita, para Souza (1992). Primeiramente, o corte geracional se torna um vetor fundamental, na medida em que os grupos estrategicamente decisivos da nova direita são os jovens tecnocratas, intelectuais, homens de negócios e políticos. O apoio deste setor ao projeto neoliberal é resultado das falhas do modelo econômico e político até então adotado. Ainda nesta chave demográfica, a base socioeconômica da nova direita é a dos "novos ricos" (o que na terminologia dos dias de hoje, chamaríamos de classe média), sobretudo nas capitais do Sudeste e do interior mais rico. 0 ataque destes grupos se dirige às "ineficiências" da máquina estatal.

A segunda questão que caracteriza a nova direita se refere aos novos caminhos para um projeto de modernização conservadora, que no caso brasileiro, "sempre combinou o conservadorismo político da direita com o progresso econômico gerado e apoiado pelo estado ${ }^{25 "}$ (Souza, 1992, p. 111). Nos anos 1980, esse projeto ganha uma nova coloração, visto que passa a se opor ao tradicionalismo econômico (ou modelo de desenvolvimento centrado no Estado) e a sua "incompetência administrativa". O darwinismo social entra como eixo importante: valorização da competição (política, econômica), que naturalmente seleciona apenas os "melhores e mais adaptados"; assim, a ideia da "cordialidade" é abolida, gerando casos explícitos de preconceitos contra migrantes nordestinos, por exemplo. Pierucci (1987) demonstrou empiricamente esses

\footnotetext{
${ }^{25}$ No original: "the Right always combined its political conservatism with the economic progress generated and supported by the state".
} 
acontecimentos, em São Paulo, com entrevistados que somavam a hostilidade com os migrantes a um discurso moralizante.

Ainda nessa chave da modernização conservadora, o apelo ao anti-comunismo já não é tão mais forte, tendo em vista o contexto de queda do muro de Berlim (1989) e do fim da União Soviética (1991). A rejeição ao comunismo, para a nova direita, se dá pela sua incapacidade de atingir o desenvolvimento econômico. Há, também, o anti-intelectualismo, posto que a prioridade é a prática (o eficiente, o pragmático, o ágil) e não o "teórico", o abstrato.

Por fim, o terceiro eixo analítico da nova direita proposto por Souza (1992) é o partidário. O Brasil, nesse sentido, reflete uma tendência já observada por Roberts (2012) para a América Latina como um todo: as associações de direita não estão habituadas a integrar partidos políticos. Tornase, pois, difícil distinguir os membros da velha direita, autoritária e amplamente associada ao regime militar, dessa nova direita - pelo menos em termos partidários. As agremiações relacionadas à nova direita, aponta a autora, até existiam no contexto do final dos anos 1980, como o PL e o PRN. Contudo, a falta de uma estrutura organizacional mais sólida é a característica principal dessa nova direita, enquanto movimento eleitoral ${ }^{26}$. No que tange à mobilização política, esse grupo é muito mais ativo através de associações presentes na sociedade civil, dos lobbies e das campanhas publicitárias - em geral, apoiadas pelo capital financeiro, setores empresariais e as grandes corporações midiáticas.

Sintetizando a análise de Souza (1992), pode-se definir a nova direita brasileira a partir de três palavras-chave: juventude, modernização e empreendedorismo. O discurso modernizador deste setor se baseia em três pontos básicos: i) privatização da esfera produtiva e dos serviços públicos; ii) mudanças na administração estatal, atribuindo-Ihe "eficiência e racionalidade"; iii) abertura do país para o mercado externo e modernização política, com a superação do corporativismo. Por meio dessas pautas, a autora argumenta que havia, naquele contexto do início dos anos 1990, sinais de dissociação entre a velha e a nova direita. Seria esse último grupo o grande responsável por inserir as propostas conservadores na agenda política nacional.

Após sua ascensão nos governos do PSDB (1995-2002) e seu refluxo, diante do crescimento das esquerdas a partir dos governos petistas (2003 - 2016), essa nova direita tem voltado a ganhar força no cenário nacional (Oliveira e Benetti, 2014; Codato, Bolognesi e Roeder, 2015). A diferença

\footnotetext{
${ }^{26}$ Souza (1992, pp. 118-119) faz uma observação, afirmando que mesmo diante dessa "fragilidade organizacional", a retórica da nova direita encontra apoio em três partidos: PFL, PDS e PMDB. Como é notável, os três estão posicionados mais ao centro e à direita do espectro ideológico.
} 
fundamental, em termos de pautas políticas, reside principalmente no papel do Estado. Se para a nova direita do início dos anos 1990 o Estado deveria ser mínimo e "ausente", na atualidade os grupos situados dentro dessa denominação não defendem o afastamento total da política e da economia. Isso se deve, sobretudo, porque esses setores perceberam que "o aparelho governamental se tornou um importante parceiro e catalizador da atividade empresarial, garantindo-Ihe uma situação de estabilidade macroeconômica" (Oliveira e Benetti, 2014, p. 10). Tal mudança foi observada durante os governos do PT, onde a parceria dos grupos empresariais com as políticas estatais resultou em crescimento econômico.

Por outro lado, a nova direita procura se desvincular da memória dos regimes autoritários - mais, ainda, do que a nova direita do início dos anos 1990. Ao mesmo tempo, ela não deixa de reconhecer e aceitar as vantagens políticas das políticas sociais implementadas pelos governos de esquerda. Nesse sentido, os partidos identificados como pertencentes à nova direita"27 "não buscam dar melhores condições materiais de vida para os cidadãos, mas sim estabelecer um pacto de igualdade de oportunidades. A igualdade de oportunidades não deve ser traduzida como igualdade plena" (Codato, Bolognesi e Roeder, 2015, p. 121). O discurso social da "igualdade de oportunidades" ganha espaço entre essas elites, mas ainda cercado por ideais como a moralização, o individualismo ${ }^{28}$, a competição mercadológica, a meritocracia, e a ideia de "eficiência da máquina pública" e do Estado mínimo. Cabe destacar, ainda, a retomada do velho discurso de combate à corrupção, utilizado pelos conservadores desde os anos 1940 (Löwy, 2015).

A nova direita dos anos 2000, ainda que dividindo matrizes comuns à chamada "velha direita", torna-se uma competidora dos partidos representantes deste segundo grupo. Ambos os grupos defendem, por exemplo, os valores da família tradicional e da não-intervenção estatal na economia (Oliveira e Benetti, 2014; Codato, Bolognesi e Roeder, 2015). Entretanto, a velha direita está diretamente vinculada ao passado com as ditaduras militares e ao autoritarismo, seja pela origem partidária ou pela existência de lideranças que, em alguma medida, colaboraram com o regime. Decorre disso que, ainda que não abertamente, essas lideranças defendem até os dias de hoje pautas como segurança pública armada e repressiva, manutenção da ordem e punição severa aos bandidos, como forma de proteger os chamados "cidadãos de bem". Além disso, esses

\footnotetext{
27 De acordo com a classificação proposta por Codato, Bolognesi e Roeder (2015), esses partidos são, majoritariamente, pequenas legendas como: PEN, PSDC, PSL e PTC, dentre outros. Ganham destaque, por conterem lideranças expressivas (regional ou nacionalmente), agremiações como PRB, PSD e SD.

${ }^{28}$ Esse tema do individualismo ganha força no discurso neoliberal e se opõe à ideia da "primazia da comunidade sobre o indivíduo", típica do chamado "velho conservadorismo", conforme explicado no início do texto.
} 
partidos e líderes promovem uma defesa mais radical da não intervenção do Estado na economia - ao contrário da nova direita que, como dito acima, aceita algumas políticas sociais como forma de incentivo ao crescimento econômico. Por fim, este grupo é adepto não apenas de valores morais sociais, mas também de uma moral cívica ${ }^{29}$, ligada a uma ideia de patriotismo e nação "fortes" - cujo objetivo máximo seria a preservação da unidade e da soberania nacionais.

Sintetizando o exposto, e para além da categorização entre a "velha" e a "nova" direita, temos em Löwy (2015) uma comparação dos grupos conservadores brasileiros com setores da extrema-direita europeia que nos ajuda a identificar temas de agitação sociocultural semelhantes. Para o autor, a ideologia repressiva, por meio do culto à violência policial e da defesa do porte de armas e da pena de morte, é um fator evidente no discurso conservador atual. Em termos partidários e institucionais, tal grupo se aglutina na chamada "bancada da bala", no Congresso Nacional (Faganello, 2015). Outro fator importante para a representação da direita brasileira, segundo Löwy (2015), é a intolerância com minorias sexuais, em particular os homossexuais. Os maiores representantes são as bancadas evangélicas neopentecostais nos Legislativos, em todos os níveis de governo.

É notável, portanto, que os conservadores têm demonstrando maior capacidade de organização e de exposição de suas pautas. Tatagiba, Trindade e Teixeira (2015) identificam o crescimento dessas mobilizações, para além dos partidos, a partir de meados dos anos 2000 . No entanto, o fortalecimento de suas representações via partidos e eleições também tem ocorrido com bastante sucesso. Mais do que isso: tal recrudescimento se baseia inclusive na identificação clara de seus representantes com o conservadorismo. O fenômeno da "direita envergonhada", que era uma marca dos políticos e elites até os anos 2000 (Mainwaring, Meneguello e Power, 2000; Madeira e Tarouco, 2010) tem ficado para trás, dando lugar e voz àqueles que se opõem a pautas progressistas - especialmente em termos de direitos humanos e de proteção às minorias.

\section{Conclusão: adesão dos conservadores aos partidos e o jogo democrático}

Após o fim dos regimes ditatoriais que dominaram a América Latina até os anos 1980, os partidos conservadores se tornaram responsáveis por canalizar, através de canais democráticos, as demandas de setores sociais e políticos até então vinculados aos regimes autoritários. Ao

\footnotetext{
${ }^{29}$ As observações deste parágrafo tiveram por base o argumento e a classificação propostos por Codato, Bolognesi e Roeder (2015, pp. 126-127) para tratar da velha direita latino-americana.
} 
representarem suas pautas na arena eleitoral, esses partidos indicam uma postura favorável à competição político-institucional com as demais agremiações, inclusive as de esquerda. Ou seja, os partidos e segmentos de direita desempenham um papel importante na legitimação das democracias, no âmbito institucional.

Power (2000), destacando este papel legitimador, atribui também outros pontos fundamentais que justificam os estudos e a importância de compreendermos a direita partidária em regimes democráticos. O autor pontua, primeiramente, que a direita é um setor social como qualquer outro e, portanto, deve ser incluído nos processos de tomadas de decisão e participação - é importante, pois, saber o que pensa e o que demanda. Especificando esta questão da representatividade, Middlebrook (2000) atribui aos partidos conservadores o papel central de potencial base representativa para os interesses políticos de longo prazo das elites, no interior de um regime democrático. Isso evitaria a busca por alternativas autoritárias, em se tratando de acesso ao Estado e suas políticas.

Um segundo argumento trazido por Power (2000), e que embasou nossa visão acerca da direita ao longo deste texto, é o de que ela ocupa postos e setores centrais no planejamento econômico nacional. Isso é reforçado para os casos latino-americanos, inclusive o brasileiro, devido à trajetória de interdependência entre Estado e elites econômicas. Justamente por conta dessa simbiose, um terceiro fator observado por Power (2000) acerca da direita é a sua capacidade de colocar pautas na agenda nacional. O exemplo mais emblemático nesse sentido ocorreu nos anos 1990, com o predomínio da pauta neoliberal.

Por fim, como afirmam O'Donnell, Schmitter e Whitehead (1986), as transições são mais bem-sucedidas quando a direita vence a primeira eleição livre. Isso não quer dizer que a relação entre democracia e adesão dos partidos de direita ao regime esteja isenta de tensões. Tal acordo de adesão ao jogo democrático tem exemplos recentes de rompimento por meio de golpes de Estado (ou parlamentares), como os casos de Honduras (2009), Paraguai (2012) e Brasil (2016). Entretanto, analisar a articulação entre democracia e partidarismo à direita nos permite captar as tensões e projetos em disputa, levando em consideração o quanto o regime democrático tem sido apoiado pelos setores conservadores. Assim, o estudo dessas agremiações torna-se central para a compreensão do arranjo democrático implementado ${ }^{30}$, sendo possível observar em que medida

\footnotetext{
${ }^{30}$ Ou como defende Power (2000), onde a direita não é de fato incorporada ao sistema democrático, há maiores chances de acontecerem intervenções militares.
} 
este segmento social tem tido capacidade de se projetar (ou não) enquanto um ator relevante dentro do sistema político, atendendo as demandas do eleitorado e se fazendo representar.

A eleição do empresário Sebastián Piñera para a presidência do Chile, em 2010, começou a colocar em cheque a "maré rosada" que predominava nos principais países latino-americanos. Os governos de esquerda, a partir de então, sofreram fortes revezes e cederam espaço para partidos e movimentos à direita, reivindicando transformações não apenas no aparato estatal, mas também na sociedade civil. A crise econômica de 2008 e o avanço de discursos liberalizantes do ponto de vista dos costumes são fatores que incidiram neste quadro. De fato, como aponta Löwy (2015), é sobretudo em períodos de crise que o conservadorismo ganha força política. O terreno social latino-americano - e especialmente, o brasileiro - tem se mostrado bastante frutífero para a expansão destes setores pelos mais diversos níveis de governos e de representação social.

\section{Referências bibliográficas}

ALBALA, A.; VIEIRA, S. M. 2014. “¿Crisis de los partidos en América latina? El papel de los partidos políticos latinoamericanos en el escenario reciente". Política, v. 52, n. 1, pp. 145-170.

ALCÁNTARA, M.; FReIdenberG, F. 2002. "Partidos Políticos na América Latina". Opinião Pública, vol. 8, n. 2, pp. 137-157.

ALCÁNTARA, M. 2004a. "Partidos políticos en América Latina: precisiones conceptuales, estado actual y retos futuro". Documentos Cidob América Latina, n. 3.

2004b ¿Instituciones o Máquinas Ideológicas? Origen, Programa y organización de los partidos latinoamericanos. Barcelona: Institut de Ciéncies Politiques i Sociales.

ALCÁNTARA, M.; VAldUVIECO, I. L. 2008. "The Parliamentary Right". In: AlCÁNTARA SÁEZ, M. (ed.). Politicians and Politics in Latin America. London: Lynne Rienner Publishers.

ALTMAN, D. et. al. 2009. "Partidos y sistemas de partidos em América Latina: Aproximaciones desde la encuesta a expertos 2009". Revista de Ciencia Política, v. 29, n. 3, pp. 775-798.

AMES, B. 2003. Os entraves da democracia no Brasil. São Paulo: FGV.

ANDERSON, P. 1995. "Balanço do neoliberalismo". In: SADER, E., GENTILI, P. (orgs.), Pós-neoliberalismo: as políticas sociais e o Estado democrático. Rio de Janeiro: Paz e Terra. 
ARNOLD, J.; SAMUELS, D. 2011. “Latin America's Left Turn? Evidence from Public Opinion: A Conceptual and Theoretical Overview". In: LEVITSKY, S.; ROBERTS, K. (orgs.). The Resurgence of the Latin America Left. Baltimore: John Hopkins.

AVELAR, L.; WALTER, M. I. M. T. 2008. "Lentas mudanças: o voto e a política tradicional”. Opinião Pública, Campinas, vol. 14, no 1, Maio.

BABIRESKI, F. 2016. "Pequenos partidos de direita no Brasil: uma análise dos seus posicionamentos políticos". Newsletter. Observatório de elites políticas e sociais do Brasil. NUSP/UFPR, v.3, n.6, pp. 1-16.

BOBBıO, N. 1995. Direita e Esquerda: Razões e Significados de uma Distinção Política. São Paulo: Editora UNESP.

BORGES, A. 2010. “Já não se fazem mais máquinas políticas como antigamente: competição vertical e mudança eleitoral nos estados brasileiros". Revista de Sociologia e Política, v. 18, pp. 167-188.

CAMERON, M.; HERSHBERG, E. (orgs.). 2010. Latin America's Left Turn: Politics, Policies and Trajectories of Change. Boulder: Lynne Rienner.

CÂNDIDO, A. 1990. "Radicalismos". Estudos Avançados, vol. 4, n. 8.

CODATO, A.; BOLOGNESI, B.; ROEDER, K. M. 2015. "A nova direita brasileira: uma análise da dinâmica partidária e eleitoral do campo conservador". In: CRUZ, S. V.; KAYSEL, A.; CODAS, G.. Direita, volver!: o retorno da direita e o ciclo político brasileiro. São Paulo: Perseu Abramo.

CRUZ, S. V. 2015. "Elementos de reflexão sobre o tema da direita (e esquerda) a partir do Brasil no momento atual”. In: CRUZ, S. V.; KAYSEL, A.; CODAS, G. Direita, volver!: o retorno da direita e o ciclo político brasileiro. São Paulo: Perseu Abramo.

; KAYSEL, A.; CODAS, G. 2015. Direita, volver!: o retorno da direita e o ciclo político brasileiro. São Paulo: Perseu Abramo.

CUEVA, A. 1989. "A guinada conservadora". In: CUEVA, A. (org). Tempos Conservadores: A direitização no Ocidente e na América Latina. São Paulo: Hucitec.

FAGANELLO, M. A. 2015. "Bancada da bala: uma onda na maré conservadora". In: CRUZ, S. V.; KAYSEL, A.; CODAS, G.. Direita, volver!: o retorno da direita e o ciclo político brasileiro. São Paulo: Perseu Abramo.

FRANZMANN, S. 2010. "Locating political parties in policy space: a reanalysis of Party Manifesto Data". Party Politics, v. 12, n. 2, pp. 151-171.

FRETEL, J. 2011. "Qual sociologia para o estudo dos partidos políticos conservadores?”. Revista Brasileira de Ciência Política, no 5, pp. 321-349. 
GIBSON, E. J. 1996. Class and Conservative Parties: Argentina in Comparative Perspective. Baltimore: John Hopkins University Press.

GIDDENS, A. 1995. Para Além da Esquerda e da Direita: O futuro da política radical. São Paulo: Editora da Unesp.

HAGOPIAN, F. 1996. Traditional politics and regime change in Brazil. Cambridge; New York: Cambridge University Press.

HERSHBERG, E. 2010. "Latin America's Left: The Impact of the External Environment”. In: CAMERON, M.; HeRShBerg, E. (orgs.). Latin America's Left Turn: Politics, Policies and Trajectories of Change. Boulder: Lynne Rienner.

HIRSCHMAN, A. O. 1992. A retórica da intransigência: perversidade, futilidade, ameaça. São Paulo: Companhia das Letras.

IANNI, O. 1989. "A Nova República do Brazil". In: CUEVA, A. (org). Tempos Conservadores: A direitização no Ocidente e na América Latina. São Paulo: Hucitec.

KAYSEL, A. 2015. "Regressando ao regresso: elementos para uma genealogia das direitas brasileiras". In: CRUZ, S. V.; KAYSEL, A.; CODAS, G.. Direita, volver!: o retorno da direita e o ciclo político brasileiro. São Paulo: Perseu Abram.

KINZO, M. D. G. 2005. "Os partidos no eleitorado: percepções públicas e laços partidários no Brasil”. Revista Brasileira de Ciências Sociais, v. 20, n. 57, pp. 65-81.

LEVITSKY, S.; ROBERTS, K. (orgs.). 2011. The Resurgence of the Latin America Left. Baltimore: John Hopkins. LÖWY, M. 2015. "Conservadorismo e extrema-direita na Europa e no Brasil". Serviço Social e Sociedade, n. 124, pp. 652-664.

LUNA, J. P.; KALTWASSER, R. (orgs.). 2014. The Resilience of the Latin American Right. Baltimore: John Hopkins University Press.

LUPU, N. 2009. "Electoral Bases of Leftist Presidents in Latin America", paper presented at the 2009 National Congress of the Argentine Association of Political Analysis, Ciudad de Santa Fe.

MADEIRA, R.; TAROUCO, G. 2010. "A "direita envergonhada" no Brasil: como partidos reinterpretam seus vínculos com o regime militar?" V Congresso Latinoamericano de Ciência Política. Asociación Latinoamericana de Ciencia Política, Buenos Aires.

MAINWARING, S.; MENeGUelLo, R.; POWER, T. 2000. Partidos Conservadores no Brasil Contemporâneo: Quais são, o que defendem, quais são suas bases. São Paulo: Paz e Terra. 
MAINWARING, S.; TORCAL, M. 2005. "La institucionalización de los sistemas de partidos y la teoría del sistema partidista después de la tercera ola democratizadora". América Latina Hoy, n. 41, pp. 141-173.

MANIN, B. 1998. Los Principios del Gobierno Representativo. Madrid: Alianza Editorial.

.2012. “A democracia do público reconsiderada”. Novos Estudos, n. 97, pp. 115-127.

MANNHEIM, K. 1981. "O pensamento conservador". In: MARTINS, J. de S. (org.). Introdução crítica à sociologia rural. São Paulo: Hucitec.

Meneguello, R.; BizzARRO NETO, F. 2012. "Contexto e Competição na Política Paulista”. DADOS - Revista de Ciências Sociais, vol. 55, n. 1.

MIDDLEBROOK, K. J. 2000. Conservative Parties, the Right, and Democracy in Latin America. Baltimore: Johns Hopkins University Press.

MONTERO, A. 2011. "Inequality and the and decline of conservatives in Brazilian democracy". Disponível em:

http://people.carleton.edu/ amontero/Inequality\%20and\%20the\%20Rise\%20and\%20Decline\%20of\%20Co nservatives.pdf. Acessado em: 30/03/2016.

O’DONNELL, G.; SCHMITTER, P.; WHITEHEAD, L. (orgs.). 1986. Transitions from Authoritarian Rule: Comparative Perspective. Baltimore: Johns Hopkins University Press.

OLIVEIRA, T.; BENETTI, P. 2014. "As novas direitas sul-americanas: análise das experiências chilena e colombiana". Observador On-line, v. 99, n. 1.

PANIZZA, F. 2005. "Unarmed utopia revisited: the resurgence of the left-of-centre politics in Latin America". Political Studies, v. 53, n. 4, pp. 716-734.

2009. Contemporary Latin America: Development and Democracy Beyond the Washington Consensus. London: Zed Books.

PIERUCCI, A. 1987. "As bases da nova direita”. Novos Estudos CEBRAP, n. 19, pp. 26-45.

POWER, T. 1996. "Elites and Institutions in Conservative Transitions to Democracy: Ex-Authoritarians in the Brazilian National Congress". Studies in Comparative International Development, vol. 31, n. 3, pp. 56-84.

2000. The political right in postauthoritarian Brazil: elites, institutions, and democratization. University Park: Pennsylvania State University Press.

2008. "Centering Democracy? Ideological Cleavages and Convergence in the Brazilian Political Class". In: KINGSTONE, P.; POWER, T. (eds). Democratic Brazil Revisited. University of Pittsburgh: Pittsburgh. 
RIBEIRO, R. L. M. 2014. "Decadência longe do poder: refundação e crise do PFL". Revista de Sociologia e Política, v. 22, n. 49, pp. 5-37.

REID, M. 2007. Forgotten Continent: the battle for Latin America's soul. New Haven: Yale University Press.

ROBERTS, K. M. 2012. "Democracy, Free Markets, and the Rightist Dilemma in Latin America". Paper presented at the annual conference of the American Political Science Association, New Orleans, August 30Sept. 2.

ROMANO, R. 1981. Conservadorismo Romântico. São Paulo: Brasiliense. . 1994. "O Pensamento Conservador". Revista de Sociologia e Política, n. 3, pp. 21-31.

SCOTT, J. 1969. "Corruption, Machine Politics, and Political Change". American Political Science Review, vol. 63 pp. 1142-58.

SINGER, A. 2002. Esquerda e direita no eleitorado brasileiro: a identificação ideológica nas disputas presidenciais de 1989 e de 1994. São Paulo: EdUSP.

SMITH, P. H.; ZIEGLER, M. R. 2009. "Democracias liberal e iliberal na América Latina”. Opinião Pública, vol. 15, n. 2, pp. 356-385.

SOUZA, M.C.C. 1992. "The Contemporary Faces of the Brazilian Right: An Interpretation of Style and Substance". In: CHALMERS, D.; SOUZA, M. C. C.; BORON, A. (orgs). The Right and Democracy in Latin America. New York: Praeger.

TATAGIBA, L.; TRINDADE, T.; TEIXEIRA, A. 2015. C. “Protestos à direita no Brasil (2007-2015)”. In: CRUZ, S. V.; KAYSEL, A.; CODAS, G.. Direita, volver!: o retorno da direita e o ciclo político brasileiro. São Paulo: Perseu Abramo.

WEYLAND, K. 2009. "The Rise of Latin America's Two Lefts Insights". Comparative Politics, v. 41, n. 2, pp. 145-164.

WIESEHOMEIER, N.; DOYLE, D. 2012. “Attitudes, Ideological Associations and the Left-Right Divide in Latin America". Journal of Politics in Latin America, vol.3, n.1, pp. 3-33. 